\title{
Göllüdağ Volkanik Kompleksi İçerisinde Kültürel ve Jeolojik Miras Öğeleri
}

\author{
The cultural and geological heritage sites within the Göllüdăg Volcanic Complex
}

\author{
M. Korhan ERTURAÇ ${ }^{1}$, Hilal OKUR ${ }^{1}$, Batuhan ERSOY ${ }^{1}$

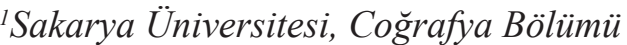 \\ (erturac@gmail.com,okurrhilal@gmail.com,batuhanersoy@yandex.com)
}

\section{öz}

İç Anadolu Volkanizması'nın en önemli volkanik sahalarından Göllüdağ Volkanik Kompleksi (GVK) ve yakın çevresinin morfolojisi, Miyosen'den en Geç Pleyistosen'e kadar devam eden volkanik faaliyetler ve sonrasında da aşınma süreçleri ile şekillenmiştir. Bölgede, nispeten dar bir alanda genç volkanizmaya dair birçok morfolojik öğe (riyolitik dom, obsidiyen akıntıları/sokulumları, skorya konileri, maar vb.) ile jeokimyasal olarak farklılaşmış volkanik ürünler (asidik ve bazaltik piroklastikler ile lav akıntıları) birbirleri ile ilişkili olarak gözlemlenebilmektedir. GVK ve yakın çevresinde bulunan jeolojik miras "Çatı Liste" kapsamında; volkanizma, jeomorfolojik yapılar, aşınma-depolama süreçleri, yer şekilleri, arazi görünümleri, tarihi ve kültürel jeositler yer almaktadır. Bölgedeki jeositlerin ana hatlarını asidik volkanizma sonucu oluşmuş riyolitik domlar ve monojenetik volkanlar oluşturur. Bu özellikleri ile bölge birçok jeolojik araştırmaya konu olmuş ve volkanizmanın özellikleri ile kronolojisi ortaya konulmuştur.

Göllüdağ, içerdiği obsidiyen oluşumları ile Anadolu'da tarih öncesi insan faaliyetleri açısından en önemli merkezlerden birisi olmuştur. Bu obsidiyen kaynakları, Paleolitik ve NeoKalkolitik dönemler boyunca alet yapımında yoğun olarak kullanılmıştır. Sahada bu kaynaklarla ilişkili çok sayıda obsidiyen işliği de bulunmaktadır. Bu özellikleri nedeniyle bölge, 1. ve 3. dereceden arkeolojik sit alanı olarak koruma altındadır. Bununla birlikte yerleşim alanları yakınlarında giderek artan altyapı faaliyetleri sonucu jeositlerde tahribat artmaktadır.

Bu çalışmada Göllüdağ yakın çevresinde gözlemlenen volkanizma ve aşınma süreçleri sonucu gelişmiş jeolojik miras niteliği taşıyan oluşumlar, bölge jeolojisi ve stratigrafisi içerisindeki konumları ile tarih öncesinden günümüze insan etkileşimi sonucu gelişmiş kültürel miras öğeleri ile ilişkileri bağlamında tanitılacaktır.

Anahtar Kelimler: Göllüdağ Volkanik Kompleksi, Jeorota, Monojenetik Volkanizma, Obsidiyen, Tarihöncesi. 


\section{ABSTRACT}

The morphology of Göllüdăg Volcanic Complex (Central Anatolia) and close surroundings has been shaped with continuous volcanism from Miocene to Latest Pleistocene and following erosional processes. The site comprises numerous geosites formed of morphological elements (asidic domes, obsidian flow/ dyke structures, scoria cones and maar) and also differentiated volcanic products (pyroclastites and lava flows) which can be classified according to the framework list of Turkey. Göllüdağ has been subject to detailed geological investigation focusing on the properties of volcanism and also the chronology.

Göllüdağ is also a well-known source of obsidian and was occupied by prehistoric activity. Göllüdağ obsidian had been widely exploited during Paleolithic and Neo-Chalcolithic for producing various chipped tools with increasing expertise. These tools were dispersed through the Middle East and Levant also even to the Cyprus especially during the Neo-Chalcolithic. Within the study area, a vast number of obsidian workshops accompany geological sites. For these reasons, Göllüdağ is protected as an archeological site of $1^{\text {st }}$ and $3^{\text {rd }}$ degrees, on the other hand, destruction related with the fast expansion and infrastructure construction within the recent settlements endanger these sites.

In this study, we will focus on the relationships geological sites formed by volcanism and erosional processes to reveal the significance of Göllüdă as a geological/cultural heritage site and introduce georoutes for recreational and scientific trips.

Keywords: Georoute, Göllüdă̆ Volcanic Complex, Monogenetic Volcanism, Obsidian, Prehistory.

\section{GİRİ̧̧}

Kapadokya Volkanik Bölgesi (KVB), İç Anadolu'nun güney kesiminde yer almaktadır. Bölgeninjeolojikvejeomorfolojik evrimiMiyosenKuvaterner yaşlı çarpışma sonrası volkanizma tarafindan kontrol edilmektedir (Pasquare, 1968; Ercan, 1987). Güneybatıda KaracadağKarapınar'dan, kuzey doğuda Erciyes Dağı'na kadar yaklaşık 300 km uzunluğında bir hat boyunca devamlı olan bu volkanik alan (Toprak, 1998), içerisinde çok fazlı volkanik faaliyetin çarpıcı yap1 ve ürünlerini barındırır (Şekil 1). Bu yapılar arasında, günümüzde çok aşınmış bir görünüm sunan Melendiz, Keçiboyduran ve Erdaş Dağları volkanları, Nevşehir-Aksaray arasında geniş bir alanda yüzeylenen ve akarsularla parçalanmış bir plato görünümü sunan ignimbrit depoları (Le Pennec vd., 1994) ile Kuvaterner yaşlı Hasandağ (3258 m) ve Erciyes (3916 m) Stratovolkanları çok belirgindir (Şekil 1). Bu önemli volkanik alanın gelişimi, özellikleri ve kronolojisi üzerine önemli çalışmalar yürütülmüştür (Pasquare, 1968; Ercan, 1987; Pasquare vd., 1988; Toprak, 1998; Aydar vd., 2012).

$\mathrm{Bu}$ çalışmanın odağı olan Göllüdă̆ Volkanik Kompleksi (GVK), KVB'nin orta kesiminde yer almaktadir. $\mathrm{Bu}$ asidik karakterli volkanik kompleks gelişimine Orta Pleyistosen'de, $12 \mathrm{~km}$ çapına sahip dairesel bir kaldera ile sonuçlanan, yüksek enerjili püskürmeler ile başlamıştır. Geç Pleyistosen'e kadar geçen zamanda ise tekil ve eklenik domların ve ilişkili obsidiyen sokulumlarının yerleşmesi gerçekleşmiştir (Mouralis, 2003; Türkecan vd., 2004). GVK'nin kuzey kesiminde ise Nar Maarı, çok sayıda skorya konisi ve ilişkili lav akıntılarını barındıran Kayırlı koridoru bulunmaktadır (Şekil 2). 
İnceleme alanı, jeolojik niteliklerinin yanı sıra içerdiği obsidiyen kaynakları nedeniyle tarihöncesi dönemlerde yoğun bir insan aktivitesine sahne olmuştur. Bölgenin, Paleolitik dönem içerisinde önemli bir uğrak alanı olduğu, alana dağılmış olarak bulunan çok sayıda el baltası ve Orta Paleolitik döneme tarihlenen obsidiyen çekirdeklerin yanı sıra önemli bir yamaç yerleşiminde (Kaletepe Dere 3) yapılan kazılarla anlaşılmıştır (Slimak vd., 2008). Göllüdağ'daki insan faaliyeti Neo-Kalkolitik dönemler içerisinde sistematik, organize ve uzmanlaşmış alet üretimi nedeniyle belirginleşmektedir. Özellikle kaynak alanlarının yakınlarında bulunan yüzlerce obsidiyen işliğinde (Ör: Kaletepe) üretilen aletlerin tüm yakın doğuya dağıldığg bilinmektedir (Balkan-Atlı vd., 1999).

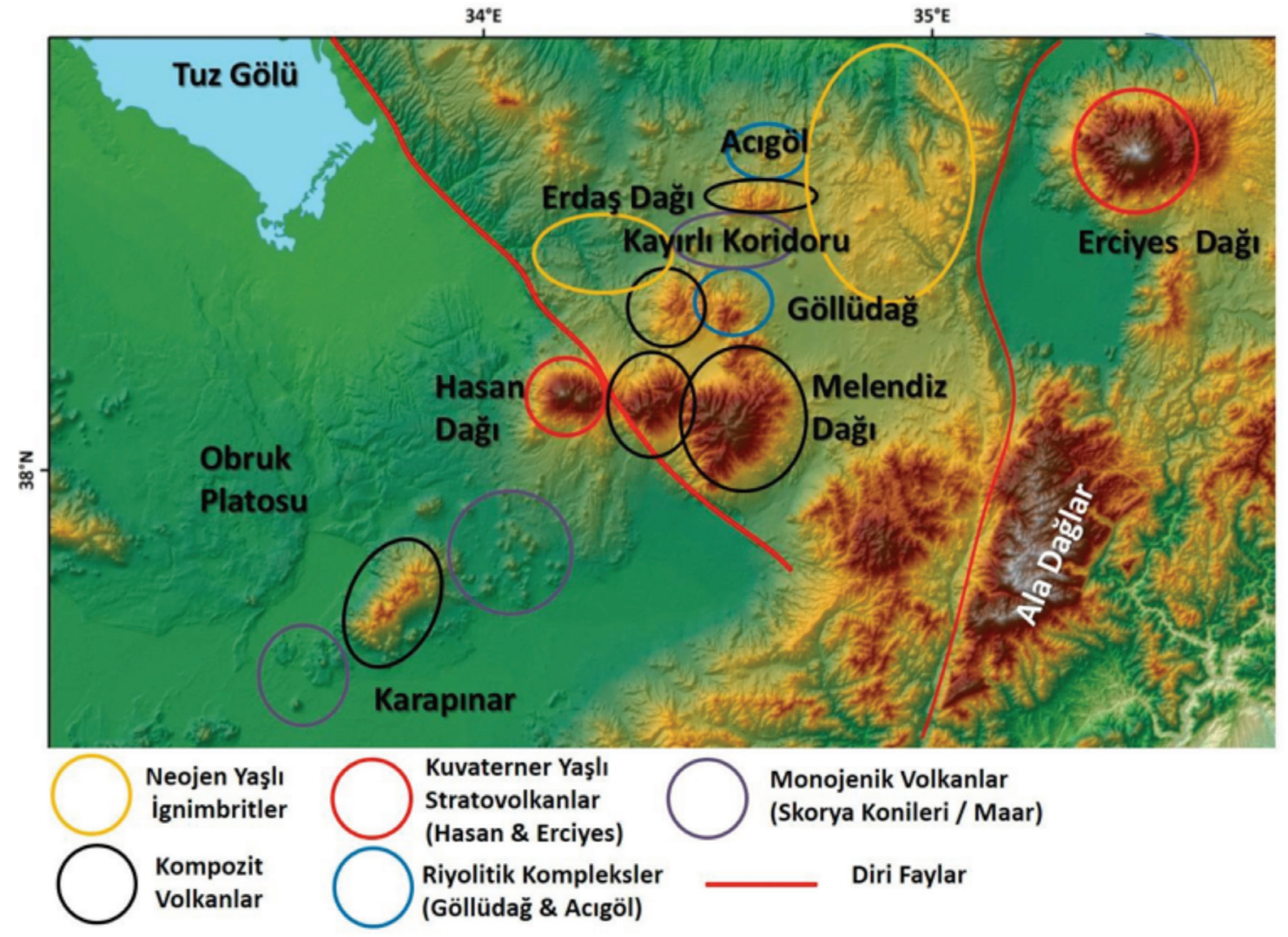

Şekil 1. İç Anadolu'nun güney kesiminin topoğrafyası ve genelleştirilmiş Miyosen-Kuvaterner volkanik bölgeleri (altlık harita SRTM yükseklik verisinden üretilmiştir)

Figure 1. The topography of the southern part of Central Anatolia and simplified volcanic centers (basemap is formed using SRTM digital elevation data)

$\mathrm{Bu}$ çalıșmada, genç volkanizma ile ilişkili jeomorfolojik yapılar, kültürel sitler ve volkanostratigrafik birimlerin dokanak ilişkilerine ideal örnekler oluşturan jeodeğerler tanitılmaktadir. Jeorotalar boyunca yerbilimi öğrencilerinin gözlemleyebilmesi için ideal bir bölge özelliğindedir. Büyük oranda arkeolojik ve doğal sit olarak tanımlı olan bölgedeki tahribat tehlikesi, madencilik faaliyetleri, artan termal turizm etkinlikleri, yerleşim yerlerinin genişlemesi ve artan altyapı çalışmaları ile yüksek şiddetteki güncel erozyon süreçleri ile ilişkilidir. 


\section{JEOLOJİK ÇERÇEVE}

İnceleme alanını oluşturan Göllüdağ Volkanik Kompleksi (GVK) ve yakın çevresindeki monojenetik volkanik alanı, İç Anadolu'nun güney kesiminde, İç Anadolu/Kapadokya Volkanik Bölgesi (KVB) olarak tanımlanan
(Pasquare, 1968; Innocenti vd., 1975; Ercan, 1987; Toprak, 1988; Pasquare vd., 1988; Bigazzi vd., 1993; Aydar vd., 1995; Kuzucuoglu vd., 1998; Gürsoy ve diğ. 1998; Mouralis, 2003; Türkecan vd., 2004, Aydar vd., 2012) ve genç volkanizma egemenliğinde jeolojik ve jeomorfolojik evrimini sürdüren bir bölgede yer almaktadır (Şekil 2).

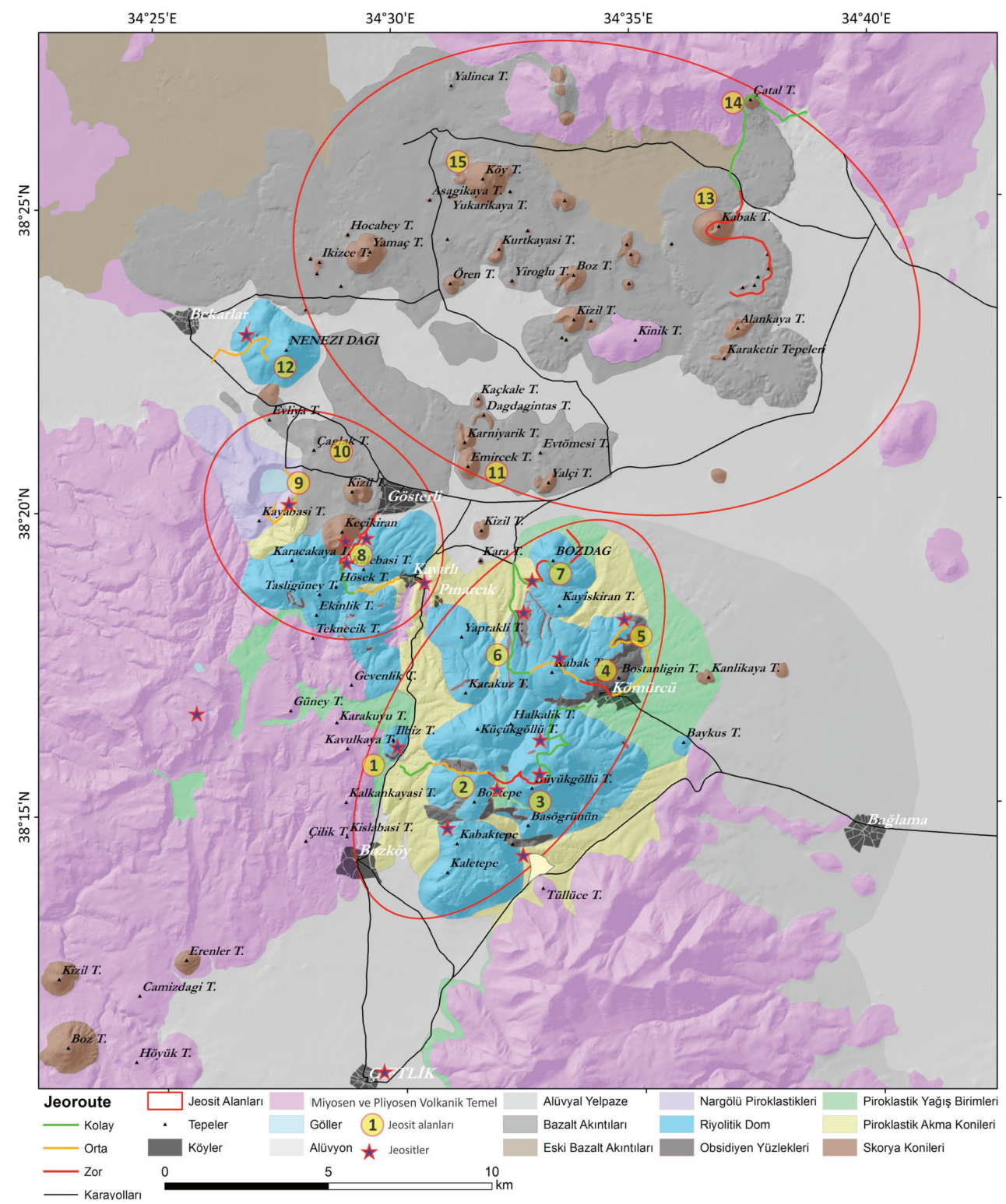

Şekil 2. İnceleme alanının genelleştirilmiş jeoloji haritası üzerinde jeopark alt alanları, seçilmiş jeodeğerler ve önerilen jeorotalar (Türkecan vd., 2004; ve Erturaç vd., 2012'den düzenlenerek)

Figure 2. The simplified geological map of the study area, showing the geovalues, georoutes and sub regions of the proposed geopark (modified after Türkecan et al., 2004 and Erturaç et al., 2012) 
KVB'nin volkanik stratigrafisi, Geç Miyosen ile Geç Pleyistosen arasında gerçekleşmiş sürekli volkanizmanın patlamalı ürünlerinden oluşmaktadır. Pasquare vd. (1988), KVB'nin oluşumu için 3 önemli aşama önermişlerdir. İlk aşama, genellikle andezitik karakterli endojen domlar ve çıkış merkezlerinin oluşumu ile tanımlanmaktadır (ör: Erdaş Dağı). Radyometrik yaş tayinleri bu dönemin 13.5 ile 8.5 my arasında sürdügünü göstermektedir. İkinci aşama, 9-8.5 ile 2.7 my arasında gerçekleşmiştir ve Melendiz Dağ1 Volkanı gibi kompozit volkanik kompleksler oluşmuştur (Pasquare, 1968; Innocenti vd., 1975;
Ercan, 1987). Kapadokya bölgesinin jeolojik gelişimin kontrol eden en belirgin volkanik faaliyetlerden birisi de $9.12-2.52 \mathrm{My}$ aralığında tarihlenen kaldera patlamaları serisinin, 400 metre kalınlığa ulaşabilen ignimbrit çökelleridir (Le Pennec vd., 1994; Aydar vd., 2012). İnceleme alanında bu volkanik seri içerisinde yer alan Kızılkaya ignimbritleri ( $\sim 5.19$ My) yüzlek vermektedir (Şekil 3). GVK’nin batı kesiminde Erken Pliyosen-Erken Pleyistosen arasina tarihlenen ( 3.6-1.71 My) Şahinkalesi bazaltik volkanizmasının ürünleri bulunmaktadır (Şekil 3).

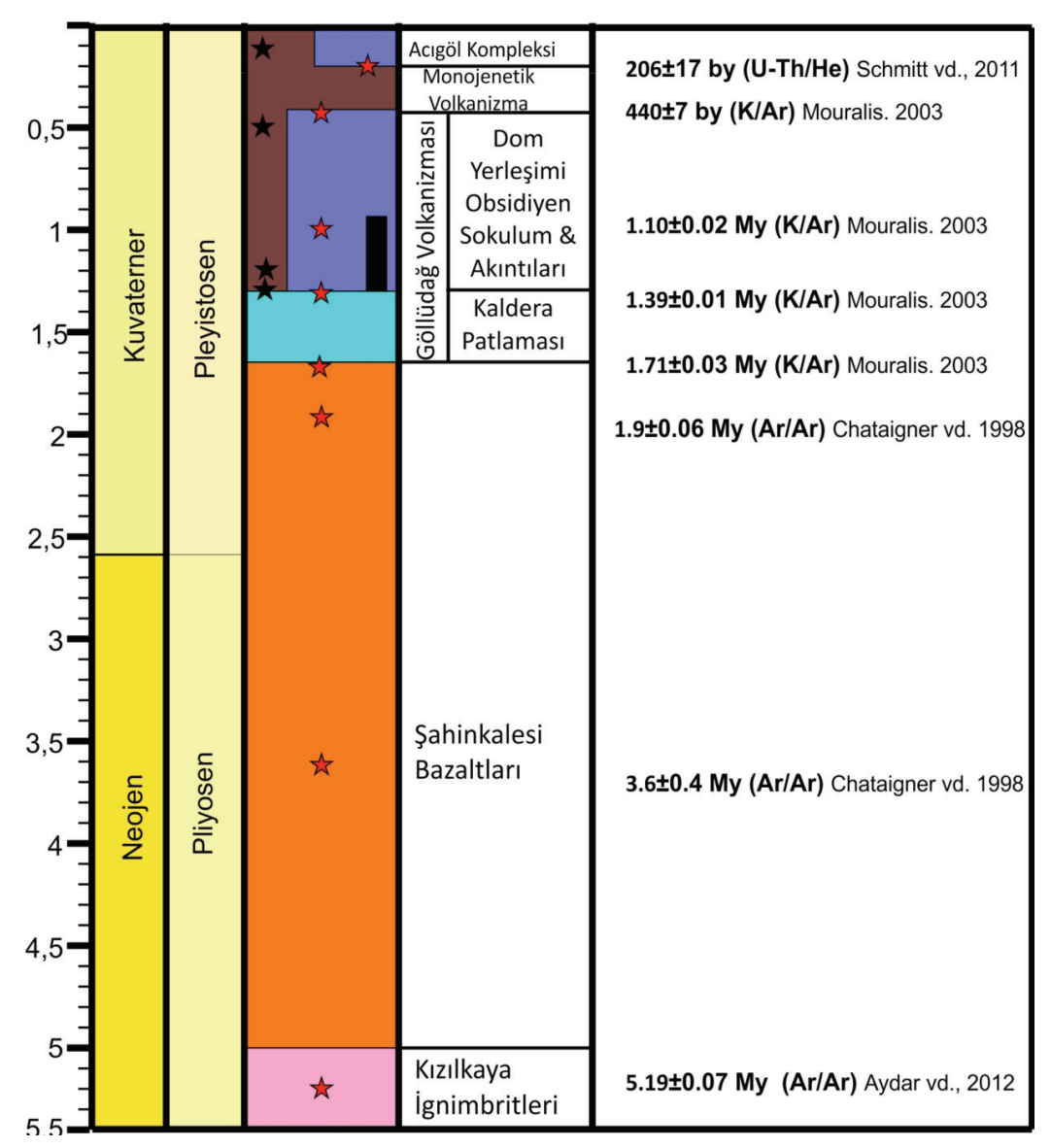

Şekil 3. Göllüdağ Volkanik Kompleksi ve yakın çevresinin volkanik stratigrafisi, yıldızlar radyometrik yaş tayinlerine karşılık gelmektedir (Chataigner vd., 1998; Mouralis, 2003; Schmitt vd., 2011; Aydar vd., 2012).

Figure 3. The volcanic stratigraphy of the Göllüdă Volcanic Complex, stars indicate radiometric dates (from Chataigner et al., 1998; Mouralis, 2003; Schmitt et al., 2011; Aydar et al., 2012) 
$\mathrm{Bu}$ çalışmanın odağını oluşturan Göllüdağ Volkanik Kompleksi dairesel bir alan içerisinde sistematik olarak gelişmiş riyolitik domlar ve ilişskili piroklastik yağış ve akıntı birimleri ile obsidiyenden oluşur. Bu birimlerden yapılan fizyon iz (FT) yöntemi (Bigazzi vd., 1993) ve $\mathrm{K} / \mathrm{Ar}$ (Mouralis, 2003) tarihlendirmelerine göre 1.71-1.39 My arasına tarihlenen büyük bir kaldera patlamasını takiben gerçekleşen asidik dom yerleşimi başlamış ve 440 binyıl önce de sonra ermiştir (Şekil 3; Mouralis, 2003). İnceleme alanın kuzeyinde kalan Acıgöl Volkanizması'nın kaldera ilişkili patlaması ise 206 binyıl önce gerçekleşmiş ve devamında da 20 binyıl öncesine kadar da dom yerleşimi devam etmiştir (Schmitt vd., 2011). Bölgede monojenetik volkanizma ise Orta Pleyistosen'den itibaren günümüze kadar devam etmektedir (Kuzucuoğlu vd., 1998, 2014; Türkecan vd., 2004)

\section{GÖLLÜDAĞ VOLKANİK KOMPLEKSİ}

Yaklaşık 12 km çapına sahip bir kaldera içerisinde bulunan Göllüdağ Volkanik Kompleksi (GVP), güneyde Melendiz Dağları (2895 m) ve Çiftlik Ovası (1550 m), batıda Şahinkale Tepesi (1990 m) kuzey ve kuzeydoğuda ise Kayırlı Koridoru ve
Derinkuyu Ovası (1300 metre) ile sınırlanmaktadır (Şekil 2). Göllüdağ Volkanik Kompleksi ve Nenezi Dağı kapsamında, kalın piroklasik akıntı ve yağış depoları tarafindan çevrelenen ve ortalama 1600 metre yüksekliğe sahip toplam 14 adet riyolitik dom tanımlanmıştır (Şekil 2). Bu domların en az 4 tanesinin, birden çok aşamada oluştuğu ve eklenik (embedded) dom olduğu belirlenmiştir (Mouralis, 2003; Binder vd., 2011). Bu domlardan Büyük Göllüdağ (2172 m), Boztepe (2068 m) ve KüçükGöllü Tepe'nin (2121 m) zirveleri 2000 metreyi aşmaktadır (Şekil 4 ve Şekil 5). Diğer domların yükseklikleri ise 1627 ve 1979 metre arasında değişmektedir. Tüm bu domlar, birbirlerinden yapısal olarak oluşmuş derin vadiler ile ayrılmaktadır. Günümüzde bölgedeki bitki örtüsü kaybı ve yağış rejimi değişikliklerine bağlı olarak artan erozyon, bu vadilerin derin deşilmesini ve hızlı yamaç aşınmasını beraberinde getirmektedir.

\section{Obsidiyen Kaynakları}

Obsidiyen, GVK içerisinde genellikle devamsız ve çeşitli boyutlarda bloklar halinde, masif ya da tabakalı riyolit seviyeleri içerisinde yüzlek verir. Birimin masif ve büyük ölçekli bir akıntı

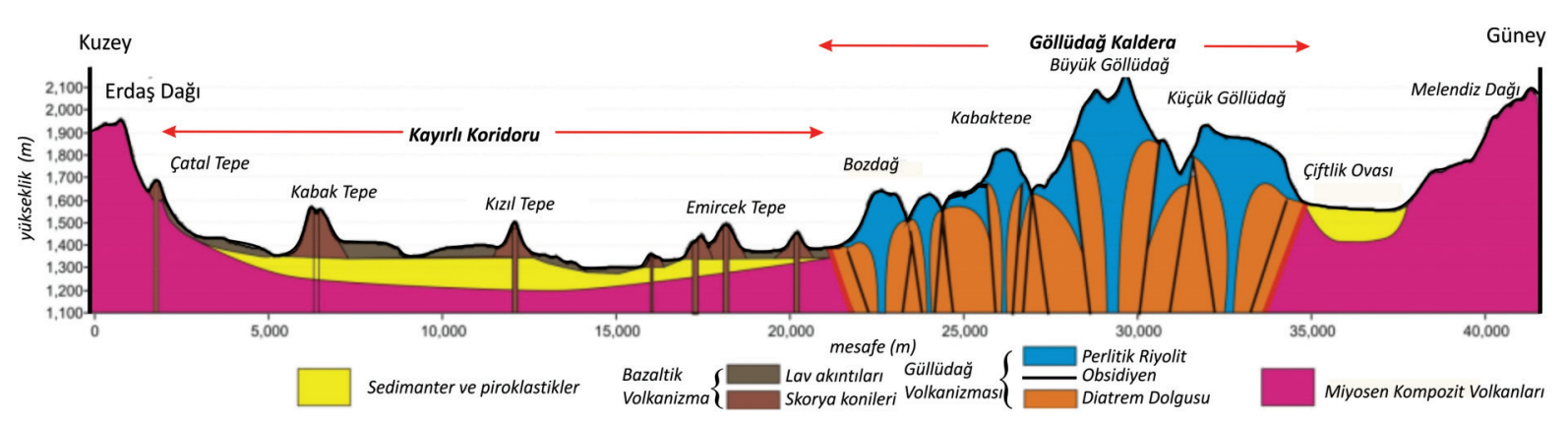

Şekil 4. Erdaş - Melendiz Dağları arasında GVK ile yakın çevresindeki volkanik birim ve yapıların enine jeolojik kesiti

Figure 4. Simplified geological cross section between Erdaş Mt. and GVC revealing the volcanic units and structures 
olarak gözlendiği durumlar ise çok nadirdir. $\mathrm{Bu}$ gözleme dayanarak, metreden kilometre ölçeğine kadar değişen boyutlarda tanımlanabilen, yerinde Göllüdağ obsidiyen kaynakları, obsidiyen içeren formasyon (OBF) olarak tanımlanmıştır (Şekil 2; Şekil 5 C; Şekil 6). OBF tanımlamasının önemli kriterlerinden birisi bu tanımlama içerisinde yer alan yüzleklerden en az birisinin alet üretimi amaçlı kullanılabilir kalite ve boyutlarda blok üretebilmesidir. Detaylı tanımlamak gerekirse, belirli bir boyutta $(10-50 \mathrm{~cm})$ bulunabilen ve litofiz, sfelürit vb. devitrifikasyon ürünleri içermeyen dolayısıyla yongalamaya uygun bu tür yüzlekler obsidiyen kaynağı (OBS) olarak tanımlanmıştır.
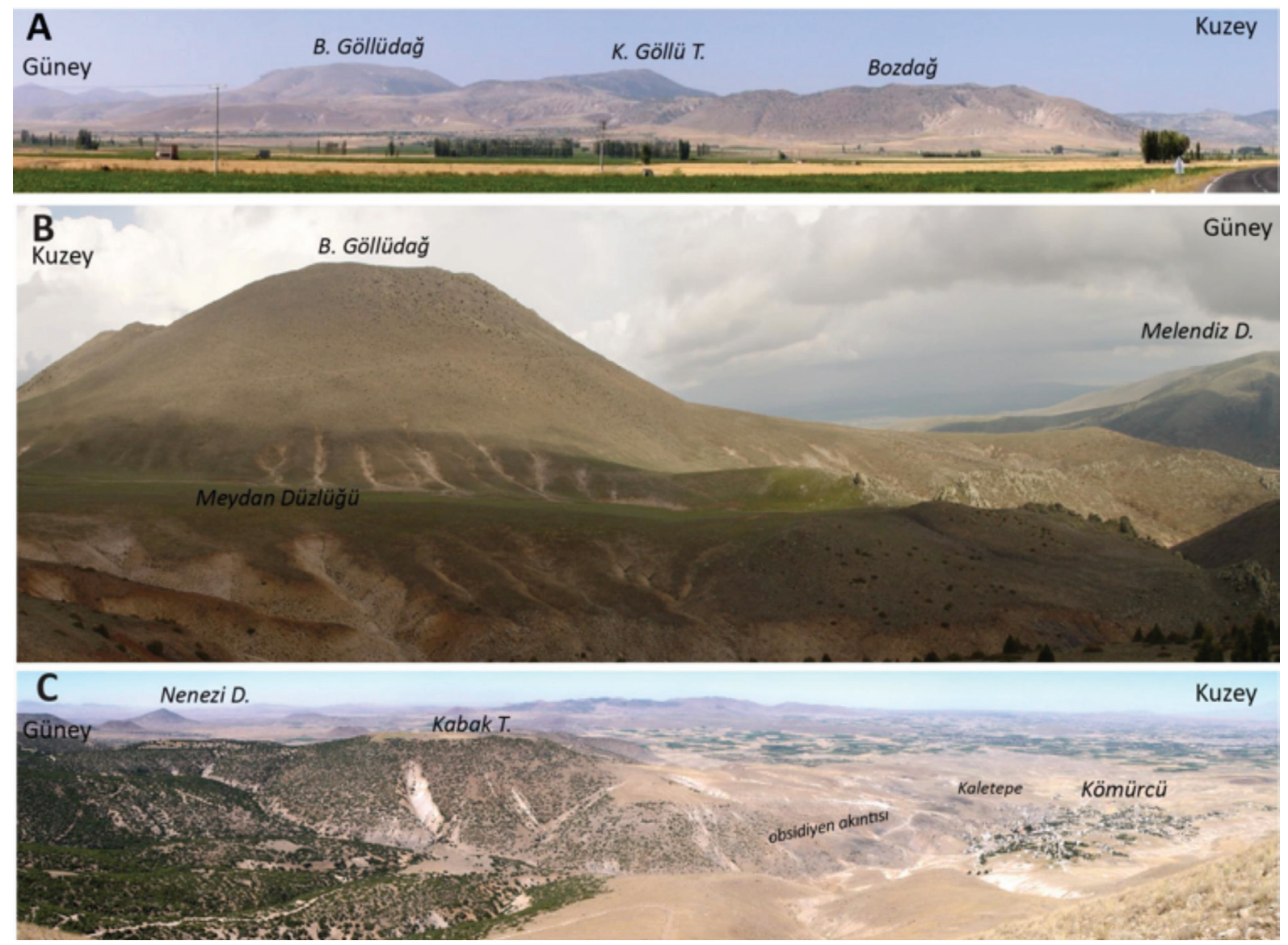

Şekil 5. (A) Doğudan batıya bakışla GVK'nın belirgin volkanlarının görünümü, (B) Küçük Göllüdağ üzerinden doğuya bakışla Büyük Göllüdağ eklenik domunun görünümü, (C) Büyük Göllüdağ üzerinden kuzeye bakışla Kabak Tepe eklenik domu ve ilişkili Kömürcü obsidiyen yatakları, arka planda Kayırlı koridoru izlenmektedir.

Figure 5. (A) East to west looking panorama of significant asidic domes of GVC, (B) East looking panorama of Büyük Göllüdağ embedded dome, looking to west, (C) North looking panorama of Kabaktepe dome showing Kömürcü obsidian sources and Kayırlı Corridor at the background 
OBF'nin harita dağılımına bakıldı̆̆ında genellikle riyolitik domların konsantrik olarak çevrelendiği gözlenir (Şekil 2). Bu konumlama, Mouralis (2003) ve Binder vd., (2011) çalışmalarında tanımlandığı gibi obsidiyenin dom yerleşiminin ilk aşamalarında yüzük dayklar halinde sokulduğu teorisini desteklemektedir (Şekil 4). Bunun yanısıra Kabaktepe Domu'nun kuzey; Nenezi Dağı'nın batı kesiminde üstte piroklastiklerle örtülü geniş yayılımlı obsidiyen akıntıları haritalanmıştır.

Şekil 6'da GVK içerisinde gözlenen obsidiyen yüzleklerine örnekler sunulmaktadır. Buna göre nadiren masif akıntı, çoğunlukla da dayk olarak sokulmuş perlitik riyolit ile ardalanmalı, değişen kalınlıkta devamsız tabakalar olarak gözlenirler.
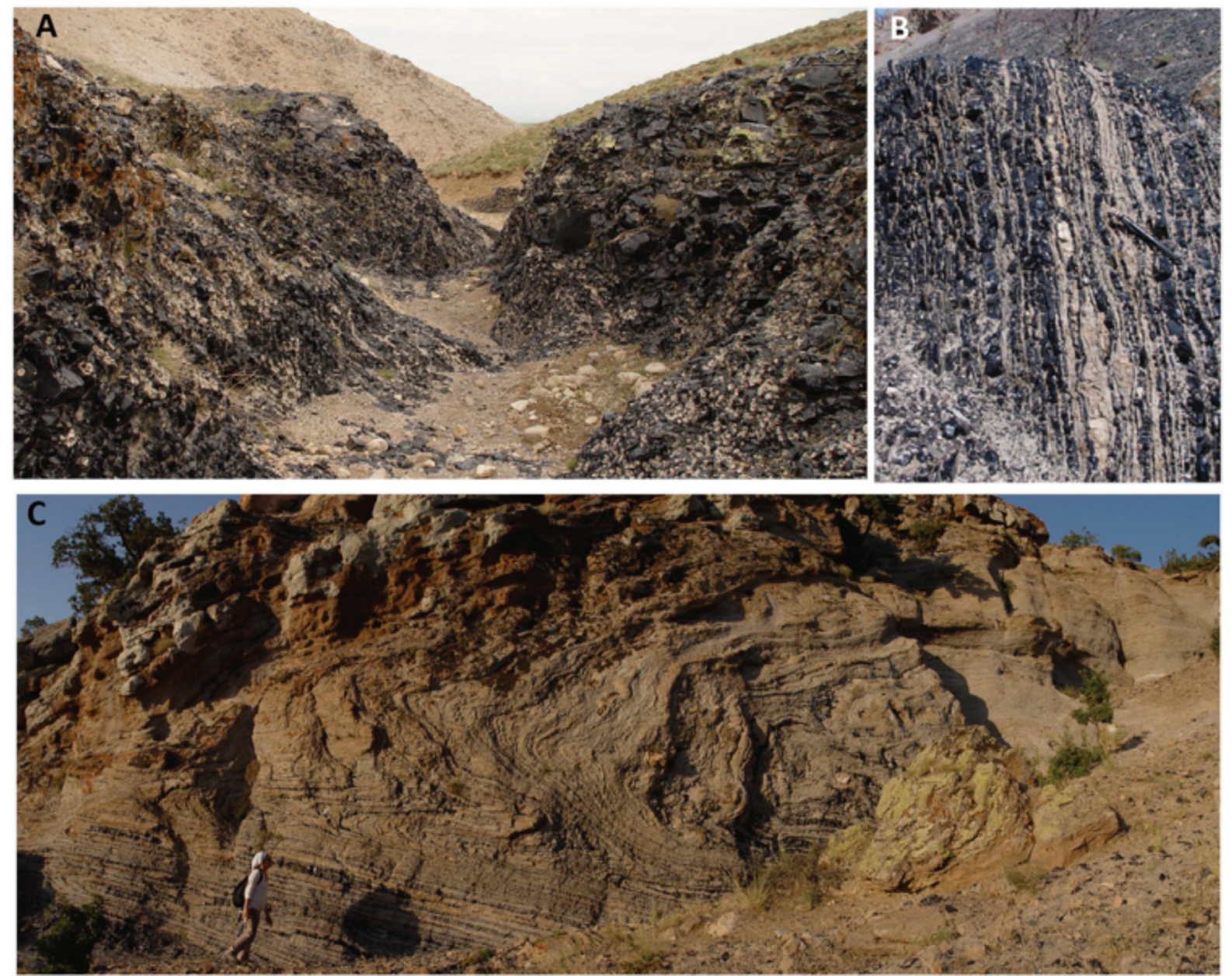

Şekil 6. GVK içerisinde gözlenen obsidiyen yüzleklerine örnekler (A) Kabaktepe batısında yer alan Erikli Dere masif obsidiyen akıntısının görünümü, (B) İlbiz Domu çevresinde perlit/obsidiyenin dike yakın tabakalar halinde ardalanması (C) Kabaktepe doğusunda yer alan perlit-obsidiyen ardalanmasında vizkoz akma yapiları

Figure 6. Examples of obsidian outcrops within the GVC, (A) Eriklidere / Kabaktepe Dome massive obsidian flow, (B) Stratified perlite/obsidian dike at Illbiz Dome, (C) Viscous flow structures in perlitelobsidian flow 


\section{KAYIRLI KORIDORU}

Doğu-batı uzanıma sahip kuzeyden Erdaş Dağ1 ve güneyden ise Göllüdağ Kompleksi ile sınırlanan Kayırlı Koridoru içerisinde Kuvaterner yaşl1 monojenetik volkanizmanın ürünü olan Nar Gölü maarı (Gevrek ve Kazanc1, 2000) ve sistematik olarak gelişmiş çok sayıda skorya konisi bulunmaktadır (Toprak, 1998; Türkecan vd., 2004). Koridorun batı sınırı Nenezi Riyolitik Domu, doğu sınırı da Derinkuyu Fayı (Şekil 1) olarak tanımlanabilir. $\mathrm{Bu}$ volkanizmanın, bölgede sistematik olarak gözlenen KB-GD yönlü faylanmanın kontrolünde geliştiği öngörülmüştür (Toprak, 1998). Koridorun doğu kesiminde Miyosen-Pliyosen yaşlı andezitik domlar (Ör: Döğdele ve Sivri tepeler) bulunmaktadır (Şekil 2). Bunların yaşlı olanları, volkanik boyunlar halinde aşınmışlardır (Toprak, 1998). Koniler içerisinde Köy, Kabak, Boz, Kızıl ve Emircek tepeler gibi belirgin morfoloji sunan olduğu gibi lav akıntıları içerisinde yer yer parazit koniler ile lav çeşmeleri gözlenir.

\section{Skorya Konileri}

Doğu-Batı uzanımlı Kayırlı koridoru çevresinde Göllüdağ Volkanik Kompleksi içindeki monojenetik volkanik faaliyete ait jeositler yer almaktadır. Geç Pleyistosen boyunca oluşan bu konilerden Çataltepe'nin yaşı $\sim<$ binyıl olarak belirlenmiştir (Türkecan vd., 2004). Farklı yaşlardaki koniler ilerleyen aşınım morfolojisine sahip olmasıyla ayırt edilebilmektedir. Bu skorya konilerinin morfolojik olarak tespit edilebilen sayısı 50'ye yakındır (Şekil 2; Şekil 7). Bu konilerin yükseklikleri 30-350 m, taban çapları ise 200-2000 m arasında (ör: Hocabey-Köy tepeler) değişmektedir. Koni gelişimi ile ilişkili yaygın bir lav akıntısı da koridoru örtmektedir. Pleyistosen yaşlı alüvyon çökellerini örten bu akıntılar koridoru dış drenaja kapalı hale getirmiştir (Kuzucuoğlu vd., 1998). Farklı fazlara ait, A’a tipindeki bazaltik lav akıntıları, koridor içerisinde inceleme alanı doğusundaki alüvyal düzlükten itibaren 200 m kalınlığında bir örtü oluşturur, son evrelere ait lav akıntılarının kalınlığ mertebesindedir (Şekil 4).

\section{Nar Gölü Maarı}

Maar, kendisinden önceki jeolojik temel ve morfoloji içerisinde gelişen ve patlama sonucunda belirgin bir çukur morfolojisi oluşturan monojenetik volkan olarak tanımlanmaktadır. Kayırlı Koridoru'nun batı sinırında bulunan Nar Maar'1 kendinden önce gelişmiş Miyosen (Selime/Kızılkaya) ignimbritleri, GVK içerisinde yer alan Karacakaya Domu'na ait piroklastik akıntı ve sonrasında Kızıltepe skorya konisi ile ilişkili (Gösterli) lav akıntıları içerisinde Geç Pleyistosen'de gelişmiştir (Şekil 8). Piroklastik üretimi açısından fakir olarak nitelendirilen maar'ın patlama ile ilişkili depoları kuzey kesiminde yüzlek verir (Gevrek ve Kazanc1, 2000). Derinliği en çok $20 \mathrm{~m}$ olan, oligosalin ve alkalin su karakterine sahip Nar Gölü, paleoklimatoloji çalışmalarında da önemli bir yere sahiptir. Güncel çalışmalar, gölün tabanında $20 \mathrm{~m}$ kalınlığında depolanan ve Geç Buzul Dönemine tarihlenen bir çökel paketinin varlığını ortaya koymuştur. $\mathrm{Bu}$ kayıtlar, bölgenin Geç Buzul-Holosen içerisindeki iklim ve vejetasyon değişimi tarihçesine 1 ş1k tutmaktadır (Roberts vd., 2016). 

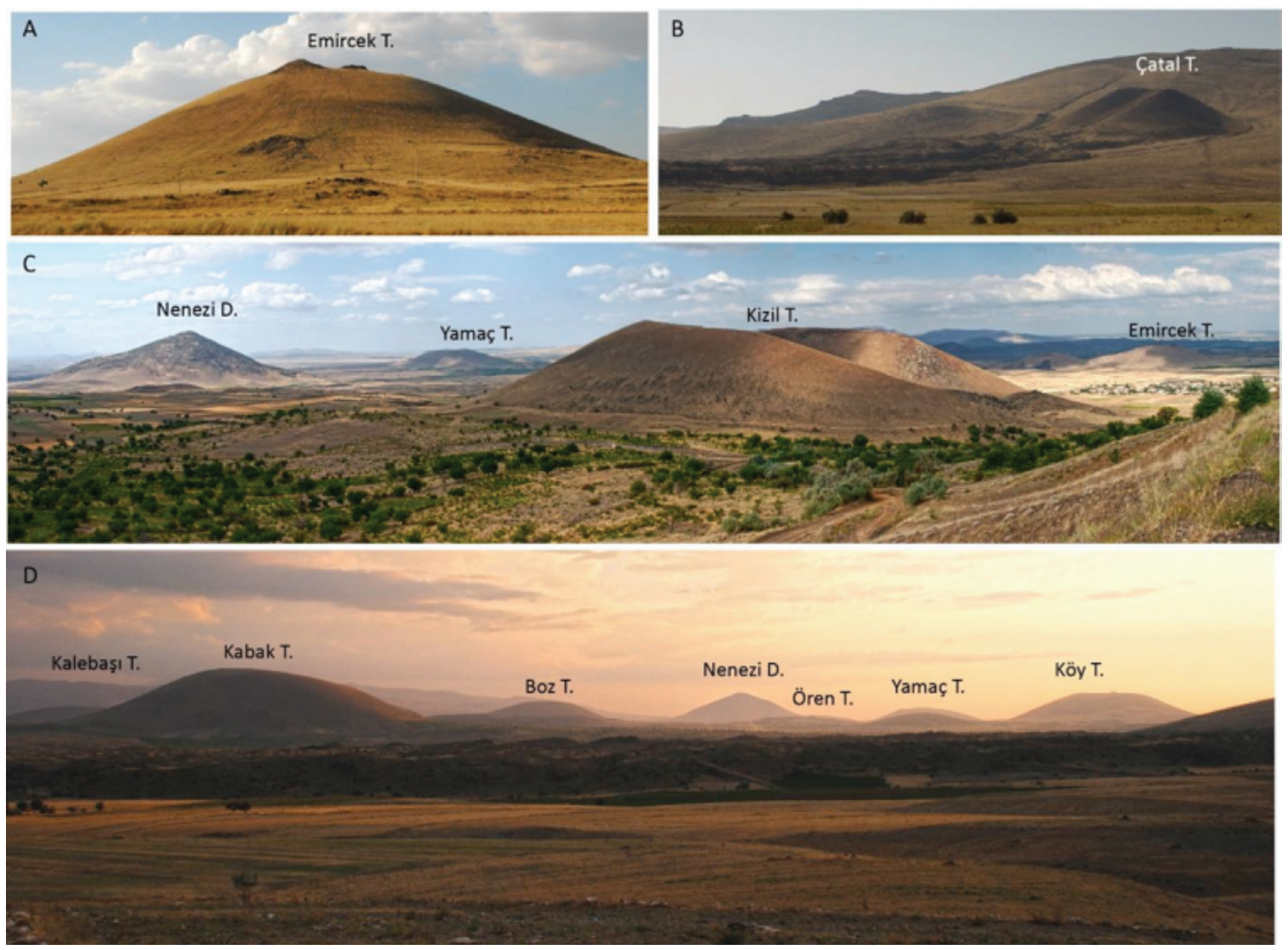

Şekil 7. Kayırlı koridoru içerisindeki skorya konileri (A) Üzerinde tarih öncesi bir tümülüs de bulunan Emircek Tepe konisi, (B) Bölgedeki en genç volkanik faaliyet sonucunda oluşmuş Çatal Tepe konisi ve ilişkili lav akıntısı, (C) Kayırlı koridorunun güneyden kuzeye görünümü (D) Kayırlı koridoru volkanlarının doğudan batıya panoramik görünümü

Figure 7. Panorama of scoria cones within the Kayırl Corridor (A) Emircek Tepe scoria cone with a prehistoric tumulus, (B) Çatal Tepe scoria cone and lava flow, (C) North to south view (D) East to west view

Maarın su toplama alanı güney kesimde daha geniştir, geriye doğru kazarak gelişimine devam eden vadi içerisinde, kısa mesafelerde akarsu oluşumunun önemli aşamaları (derecik, dev kazanları, kanal ve fan/delta) gözlenebilmektedir. Yine bu kesimde yüzlek veren ignimbritler hızlı aşınma nedeniyle gelişen kırgı bayırı topoğrafyası sunar ve içerisinde MS 1000 sonrasına tarihlenen tescilli yerleşim ve ibadet alanları bulunmaktadır (Açıkgöz vd., 2009). Maar'ın oluşumunu kontrol eden birincil ve çökmesi sırasında oluşan ikincil faylanma, bölgenin jeolojik geçmişini ortaya koyan birçok doğal kesitin oluşmasını sağlamıştır (Şekil 8 A). Gölün iç çeperini dolaşan ana yolun yanısıra güneydoğu kesimindeki patika boyunca volkanik stratigrafi ve birimlerin birbirleriyle dokanak ilişkisi çok belirgin olarak gözlenir. $\mathrm{Bu}$ birimler D-B ve K-G doğrultulu normal faylar tarafından kesilerek yanyana getirilmiştir (Şekil 8 B). Yerinde bir ilişkiye örnek olarak obsidiyen içeren Göllüdağ piroklastikleri ile bazaltik lav akıntıları arasındaki sıcak dokanak gösterilebilir (Şekil 8 C). 

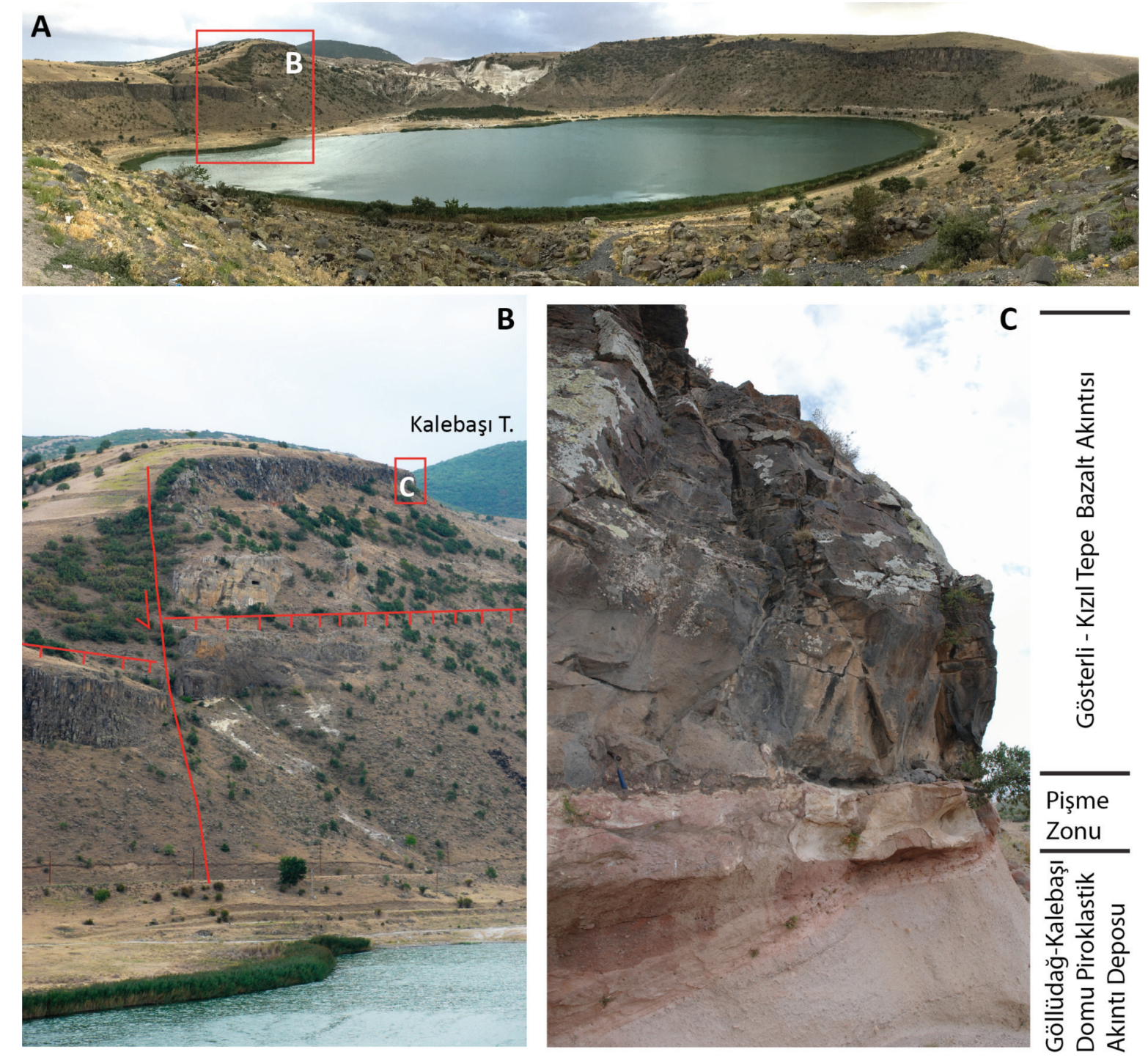

Şekil 8. (A) Nar Gölü Maarının kuzeyden güneye bakışla genel görünümü (B) Maarın doğu duvarında gözlenen D-B ve K-G doğrultulu normal faylar (C) Göllüdağ piroklastikleri ve bazaltik lav akıntıları arasındaki sıcak dokanak ilişkisi

Figure 8. (A) North to south panorama of Nar lake Maar, (B) E-W and N-S trending normal faults observed at the eastern wall of the maar, (C) Hot contact between acidic pyroclastics of Göllüdağ and basaltic lava flows.

Nar Gölü, maarın kuzey dış sınırında yakın dönemde inşaa edilen ve halen inşaatı devam eden termal tesisler ile turizm faaliyetine açılmıştır, bunun yanısıra günübirlik rekreasyonel alan olarak da yöre halkı tarafından kullanılmaktadır. $\mathrm{Bu}$ faaliyetler doğal sit alanı statüsüne sahip maar içerisinde tahribata yol açmaktadır.

\section{GÖSTERLİ VADİSI}

Gösterli Vadisi, inceleme alanı içerisindeki en renkli jeorotalardan birisidir. Gösterli Köyü'nden başlayarak Kalebaşı ve Keçikıran Tepeleri arasında yaklaş1k $2 \mathrm{~km}$ uzanan bu rota boyunca, farklı evrelerde gelişmiş volkanizmanın yapı ve ürünleri arasındaki ilişkiler gözlenmektedir. (Şekil 
9 A). Bu birimler, Miyosen yaşlı ignimbritler, Göllüdağ piroklastikleri ve Kalebaşı domu ile riyolitler üzerinde gelişmiş Keçikıran skorya konisidir. Rota, Gösterli Köyü yakınlarında başlar. İlk kesimlerinde, ignimbritler içerisine kazılmış ve MS 1000 yılına tarihlenen yaygın bir yerleşim alanının kalıntıları izlenir. bir riyolit blok içerisinde açılmış dar bir boğazdan geçer. $\mathrm{Bu}$ blok vadi gelişiminde önemli kütle hareketlerini de yansitmaktadır. $\mathrm{Bu}$ kesiminde hızlı aşınma ile fosilleşmiş çökel kanal yapıları da izlenir (Şekil 9 C).

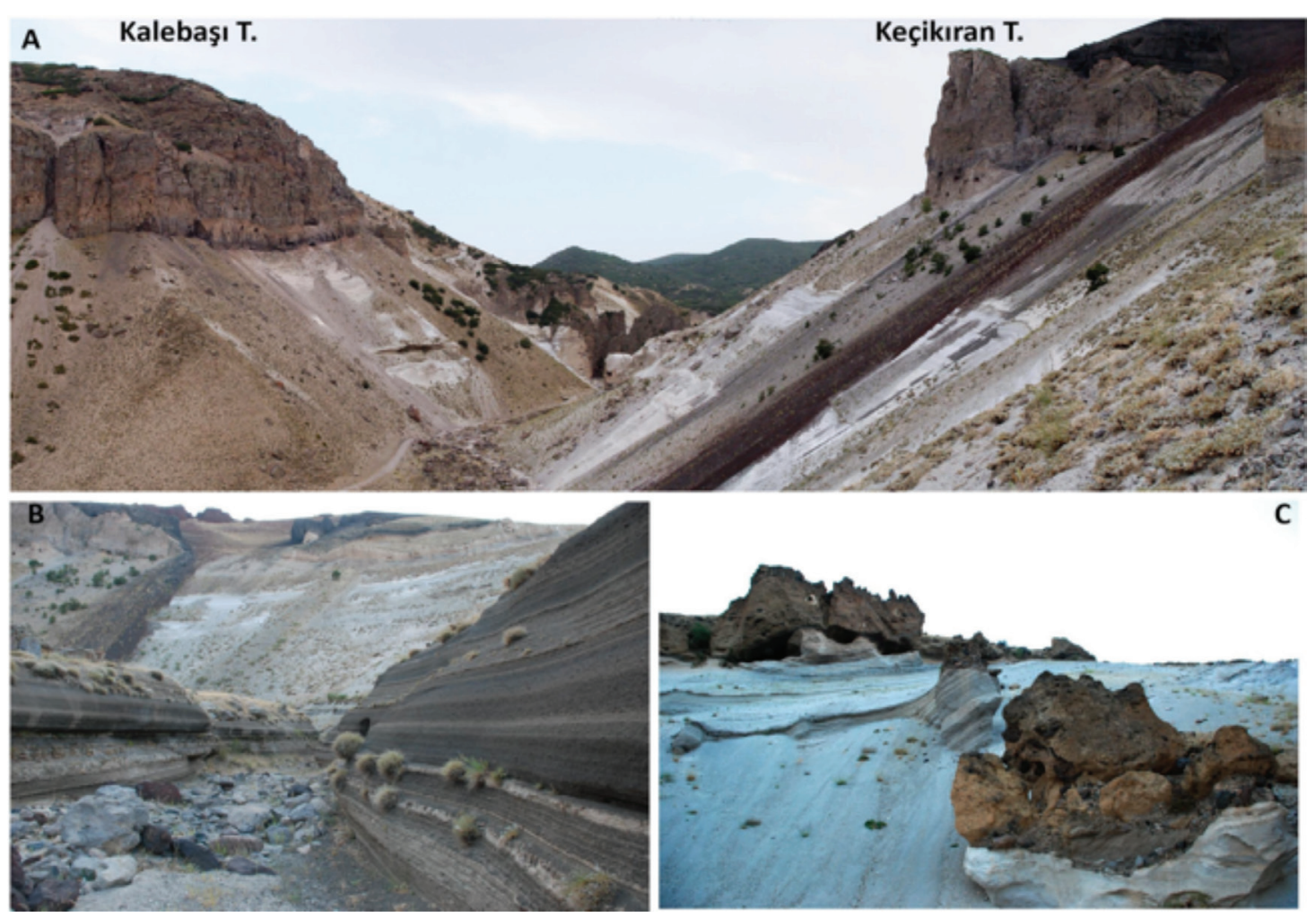

Şekil 9. Gösterli Vadisi jeorotası (A) Vadi ve yamaçlarının genel görünümü stratigrafik ilişkiler (B) Dere tabanındaki güncel aşınma ile gözlenen kesitler (C) Hızlı aşınma, kütle hareketlerini ve taraçalardaki çökel depolarının yerel olarak korunmasını kontrol etmektedir

Figure 9. Gösterli Valley georoute: (A) General panorama showing stratigraphical relationships, (B) Sections formed after erosion, (C) Mass movements, rock falls related with fast erosion and fossilized alluvial channel terrace

Vadi, Göllüdağ Volkanizması'nın yatay tabakalı, mafik ve felsik ardalanmalı yağış ve akış depoları içerisine hızla, menderes geometrisi sunarak gömülmektedir. Bu kesiminde tabanında ve taraçalarında oldukça çok sayıda riyolit blok, obsidiyen ve volkan bombası çökel bloklar olarak bulunur (Şekil 9 B). Vadi, üst kesimlerinde büyük

\section{JEOLOJIKK MİRAS}

\section{Jeodeğerler}

İnceleme alanı içerisinde önceki kısımlarda detaylandırılan birçok jeodeğer bulunmaktadır. $\mathrm{Bu}$ jeodeğerlerin en belirgin olanları aşağıda listelenmiş ve Şekil 2'de konumları belirtilmiştir. 
Buna göre üç alt bölgede 15 jeodeğer tanımlanmıştır.
A. Göllüdağ ve çevresi
1. İlbiz asidik domu, obsidiyen yüzlekleri ve tarih öncesi işlikleri

2. Gökdere vadisi obsidiyen yüzlekleri ve tarih öncesi işlikleri

3. Büyük Göllüdağ krater gölü ve Geç Hitit yerleşmesi

4. Kömürcü obsidiyen akıntıları ve Kaletepe Neolitik işliği

5. Eriklidere masif obsidiyen akıntısı

6. Bitlikeler obsidiyen akıntısı ve tarih öncesi işlikleri

7. Bozdağ tekil asidik domu ve ilişkili yapılar

B. Nargölü Maarı-Kalebaşı Tepe ve Gösterli Dere çevresi

8. Gösterli Deresi Vadisi rotas1

9. Nar Gölü Maarı

10. Kayırlı koridoru güney kesimi AA tipi lav akıntıları ve ilişkili yapılar

C. Kayırlı koridoru skorya konileri ve lav akıntıları

11. Karnıyarık ve Emircek tepe skorya konileri

12. Nenezi Dağı asidik domu

13. Kabaktepe skorya konisi ve lav akıntıs1

14. Çataltepe skorya konisi ve lav akıntısı

15. Köytepe skorya konisi ve lav akıntıs1

$\mathrm{Bu}$ jeodeğerler içerisindeki Kayırlı Köyü güneydoğusu (Kabak Tepe) obsidiyen oluşumları, Nenezi Dağı, Nar Gölü Maarı, Kızıl Tepe, Çatal Tepe skorya konileri ve lav akıntısı, Ahmet Türkecan tarafından önerilmiş ve Jeolojik Mirası Koruma Derneği (JEMIRKO) tarafından
2003 y1lında yayınlanan Türkiye jeolojik miras envanteri içerisinde yer almıştır. $\mathrm{Bu}$ yapılar, Türkiye Çatı Listesi (Kazancı vd., 2015) ile belirlenmiş on ayrı kategori ya da grup içerisinde, a-Stratigrafik, c-Volkanik petroloji, dokular ve yaplar, olaylar ve provensler, $f$ - jeomorfolojik yapılar, aşınma-depolama süreçleri, yer şekilleri, arazi görünümleri, j-tarihi ve kültürel jeositler tanım ve kapsamı içerisine girmektedir.

\section{Jeorotalar}

Göllüdağ Volkanik Kompleksi, belirgin yüksek yamaç eğimine sahip volkanlardan oluşmaktadır. $\mathrm{Bu}$ nedenle çevresini dolaşan ve köyleri birbirlerine bağlayan karayolu dişında araç ulaşımına uygun değildir. Bununla birlikte çalışma alanında tanımlanan birçok jeodeğer ve arkeolojik sitlerin gözlemlenebileceği, çeşitli zorluk derecelerine sahip, yürüme rotaları önerilmektedir (Şekil 2). Günübirlik olarak gezilebilecek bu rotalardan dört tanesi tanımlanmıştır. Buna ek olarak Gösterli Vadisi-Kayırlı Köyü arasındaki 4 km uzunluğundaki rota, yine günübirlik olarak katedilebilir. Nar Gölü ve Kayırlı Koridoru boyunca jeositlere araç ile yaklaşmak mümkün olabilmektedir. Bununla birlikte en güzel yüzlekler, her zamanki gibi patikalarda, keçi yollarında ve dik yamaçlarda gözlenmektedir.

\section{Arkeolojik Sitler}

Volkanik Kapadokya olarak adlandırılan İç Anadolu'nun güney kesimi, tarih öncesi dönemlerde yaygın insan faaliyetine sahne olmuştur. Bunun en önemli nedenlerinden birisi olarak Göllüdağ obsidiyen kaynakları gösterilmektedir. İlk kez Renfrew (1969) tarafindan buluntulanan bu kaynaklar, Paleolitik ve 
Neo-Kalkolitik dönemler boyunca alet yapımında yoğun olarak kullanılmıştır (Balkan-Atlı ve Der Aprahamian, 1998; Slimak vd., 2008; Kuhn vd., 2015). Göllüdağ kaynaklı obsidiyen aletler, süs ve prestij eşyaları İç Anadolu'daki önemli tarih öncesi yerleşimlerde (Tepecik-Çiftlik, Çatalhöyük ve Aşıklı Höyük) yaygın olarak bulunmakta, karakteristik üretim teknolojileri ile de NeolitikKalkolitik dönem (MÖ 8000-6000) içerisinde Anadolu'dan Kibris ve Mezopotamya'daki önemli yerleşimlere kadar geniş bir alanda dağılım göstermektedir (Cauvin ve Chataigner, 1998). Göllüdağ içerisinde süregelen yüzey araştırmaları ile, amaca uygun boyut ve niteliklerde her yüzlek çevresinde Neolitik-Kalkolitik döneme tarihlenen işlikler yer alır (Balkan-Atlı vd., 1999). Bunlardan en önemlisi ise Kömürcü Köyü'nde bulunan Kaletepe işliğidir (Balkan-Atlı ve Der Aprahamian, 1998). Alanda paleolitik döneme tarihlenen çekirdek ve el baltaları da yaygın olarak bulunur (Şekil 10 A; Slimak vd., 2008; Khun vd., 2015).

A
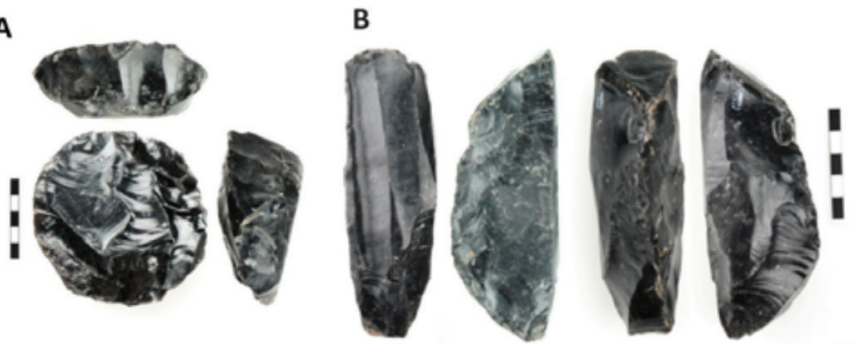

Büyük Göllüdağ'ın zirvesinde, mevsimlik birgölilekrateri tamamen çevreleyen ayaktakalmış bir sur ile birlikte Geç Hitit dönemine tarihlenen bir yapı kompleksi/yerleşim bulunmaktadır (Şekil $10 \mathrm{~B})$. Bu yerleşime ulaşımı sağlayan ve zirveden batıdan güneye doğru dönerek inen bir yol da kısmen korunmuştur. Dağın kuzey kesiminde Bronz Çağına tarihlenen bir höyük yer alır. Bahsedilen kültürel miras öğeleri büyük oranda tescillidir ve uluslararası bilimsel araştırmalara konu olmuştur (Açıkgöz, 2009)

\section{Tahribat Tehlikesi}

İnceleme alanı, büyük oranda 1. ve 3. derece arkeolojik ve doğal sit alanı olarak tescillidir. $\mathrm{Bu}$ koruma statüsüne rağmen, bölge asidik domların temel yapıtaşı olan perlit nedeniyle yakın dönemde açık madencilik işletmelerinin hedefi olmuştur. Bununla birlikte, artan termal turizm faaliyetleri, yerleşim yerlerinin genişlemesi ve yeniden yapılanmasını takiben artan altyapı çalışmalarının

Şekil 10. Göllüdağ çevresindeki yüzey araştırmaları ve arkeolojik kazılardan elde edilen aletler: (A) Kaletepe Dere III Kazısından Orta Paleolitik, Levallois çekirdek Slimak vd., (2008), (B) Neolitik Döneme (Kaletepe İşliği) ait çekirdek, (Göllüdağ Kazı Arşivi \#268, Balkan-Atlı vd., 2011). (C) Göllüdağ zirvesinde bulunan geç Hitit yerleşiminin hava fotoğrafı (Foto: Yasin Gökhan Çakan)

Figure 10. Archaelogical artefacts revealed during surface expeditions and excavations: (A) Middle Paleolithic Levallois obsidian core (Slimak et al., 2008), (B) Neolithic core from Kaletepe workshop (Göllüdağ Excavation Archive \#268, Balkan-Atlv et al., 2011), (C) Aerial picture of Late Hitite settlement located at the top of Büyük Göllüdağ dome (Photo by: Yasin Gökhan Çakan) 
yakın gelecekte bölgede önemli tahribata yol açacağ1 öngörülebilir. Bir diğer tahribat unsuru ise yaygınlaşan kaçak kazı aktiviteleridir.

\section{SONUÇ VE ÖNERILER}

$\mathrm{Bu}$ makalede belirli bir oranda detaylandirılan ve tanıtılan jeodeğerler, Jeosit tanımı içerisine girmektedir. Kısa bir tanımla "yok olması durumunda bulunduğu bölgeye ait bilgi ve jeolojik bir belgenin kaybolacă̆l, nadir bulunan, yok olma tehdidi altındaki değer" (Kazanc1, 2010) olan jeositler bir jeopark içerisinde tanımlanarak korunabilir. $\mathrm{Bu}$ anlamda, Göllüdağ'ın yaklaşık $500 \mathrm{~km}^{2}$ alan kaplayan jeopark potansiyelinin, yerel yönetimler bazında farkındalığın arttırılması ile koruma, eğitim ve sürdürülebilir kalkınma olarak tanımlanan UNESCO "Küresel Jeopark Ağı” ilkeleri göz önünde bulundurularak değerlendirilmesi uygun olacaktır.

\section{KATKI BELİRTME}

$\mathrm{Bu}$ çalışma, bölgede Kültür Bakanlığ 1 desteğinde kesintisiz devam eden arkeolojik araştırma ve projeleri kapsamında 2010 y1lından itibaren gerçekleştirilen arazi çalışmaları süresince şekillenmiştir. Yazarlar destekleri için Dr. Laurence Astruc (Obsidiennes, Pratiques techniques et Usages en Anatolie; 2009-2012); İÜ Arkeoloji Bölümü öğretim üyeleri Prof. Dr. Nur Balkan-Atlı (Göllüdağ Yüzey Araştırması; 2007-2013) ve Doç. Dr. Erhan Bıçakçı (Tepecik-Çiftlik Tarihöncesi Kazısı 2000- ve Melendiz Araştırmaları) ile Catherine Kuzucuoğlu ve Damase Mouralis'e teşekkürü bir borç bilir.

\section{EXTENDED SUMMARY}

Cappadocia Volcanic Provence (CVC, Toprak, 1998) is located at the south of Central Anatolia. The geological and geomorphological evolution of the region is dominated by continuous MioceneQuaternary post-collisional volcanism (Pasquare, 1968; Ercan, 1987). The region extends for some $\sim 300 \mathrm{~km}$ from $\mathrm{SW}$ (Karapinar-Karacadağ) to NE (Erciyes Mt.), covered by the products and monuments of extensive, multi-phased volcanic activity. These structures can be listed as: Neogene Melendiz, Keçiboyduran ve Erdaş composite volcanoes, which are intensively eroded, a wast and thick ignimbrite covering a wide region between Aksaray and Nevşehir cities (Le Pennec et al., 1994). The Quaternary stratovolcanoes namely Hasan (3258 m) and Erciyes (3916 m) are very distinct by means of morphological expression and their activity is recorded during prehistory and historical periods. The volcanic evolution of the region by means of stratigraphy, geochemistry and chronology was subject to numerous studies (i.e. Pasquare, 1968; Ercan, 1987; Pasquare vd., 1988; Toprak, 1998; Aydar et al. 2012)

This study focuses on the significant geological properties and geo-tourism potential of Göllüdağ Volcanic Complex (GVC), which is located at the centre of CVP. This acidic volcanism started its evolution with a $15 \mathrm{~km}$ wide elliptical caldera explosion during Middle Pleistocene, and individual dome extrusion until Late Pleistocene (Mouralis, 2003; Türkecan et al., 2004). There are 14 individual domes within the GVC, all surrounded with pyroclastic fall and flow deposits related with caldera and maar eruptions. The domes also produced obsidian, which intruded as ring dykes or rarely massive flows. These obsidian has been extensively used as a source for lithic tool production through prehistory. 
There is an E-W trending Late Pleistocene monogenetic volcanic field with numerous (> 50) scoria cones, related lava flows and a wide maar. Some of these cones are very young and dated as $<5$ ka by K/Ar (Türkecan et al., 2004). The relative height of these cones varies between 50-350 $\mathrm{m}$ and basal diameter as 200-2000 $\mathrm{m}$. The cones can also be classified according to the erosion of their slopes. The total thickness of the lava flow is $200 \mathrm{~m}$ and observed as stratified where one can differentiate different phases of the monogenic volcanism. The Late Pleistocene Nar maar cuts through the volcanic stratigraphy of the study are and exposes the contact relationships of these units along its rim. The maar exhibits $\sim 20$ $m$ of Late Pleistocene deposits and shed light on climate changes of the region since Late Glacial period (Roberts et al. 2016).

The study area was subject to prehistoric human activity, directly related to the obsidian sources. The long lasting surface expeditions and site excavations revealed Paleolithic occupation and settlement (Kaletepe Dere 3) with many individual scarper findings and levallois cores (Slimak et al., 2008; Khun et al., 2015) scattered through the GVC (Balkan-Atll et al., 2011). This occupation continued during Neolithic and Chalcolithic periods, identified with extreme and mass production of obsidian tools within numerous workshops (Balkan-Atl et al., 2011). These tools expressed keen expertise and were exploited throughout all the Near East (i.e. Kaletepe workshop; Balkan-Atl and Der Aprahamian, 1998). The nearby prehistorical sites (i.e. TepecikCiftlik and Asikli Höyük) flourished with this valuable lithic source and practiced occupation and domestication during Pre-Pottery Neolithic and Chalcolithic periods.
The cultural and geological sites of the study area are partially reported within the framework lis of geosites and geological heritage in Turkey (Kazancı et al., 2003) and classified as a-stratigraphic, c-Volcanic petrology, pattern and structure, events and provences, f-geomorphological structures, erosionaldepositional processes, landforms, landscapes, and $j$-historical and cultural geosites (Kazancr et al., 2015).

The focused site presents perfect examples for an earth-science student to understand the relationships of effusive volcanism of different eruption styles and products accompanied with prehistoric human activity. The defined geo-routes for daily tracking covers most of these geosites. These sites are today vulnerable to accelerating erosion and also perlite mining facilities, urban growth. Therefore we propose that Göllüdağ should be regarded and valued as a geopark by local authorities. A geopark is defined as " a single, unified geographical area where sites and landscapes of international geological significance are managed with a holistic concept of protection, education and sustainable development" as described by UNESCO Global Geoparks Network.

\section{DEĞIINILLEN BELGELER}

Açıkgöz, F., Demir, F., Eryaman, M., Tektaş, M., 2009. Niğde İli Kültür Envanteri, 463 sf, T.C. Niğde İli Valiliği, İl Kültür ve Turizm Müdürlüğü, Niğde Müzesi yayınları.

Aydar, E., Gourgaud, A., Deniel, C., Lyberis, N., Gundogdu, N., 1995. Le volcanisme quaternaire d'Anatolie centrale (Turquie): association de magmatisme calco-alcalin et alcalin en domaine de convergence. Canadian Journal of Earth Sciences 32 (7), 1058-1069. 
Aydar, E., Schmitt A.K., Çubukçu E., Akin L., Ersoy A., Şen E., Duncan, R.A., Atici, G., 2012. Correlation of ignimbrites in the central Anatolian volcanic province using zircon and plagioclase ages and zircon compositions. Journal of Volcanology and Geothermal Research 213-214. 83-97.

Balkan-Atl1, N. and Der Aprahamian, G., 1998. Les nucléus de Kaletepe et deux ateliers de taille en Cappadoce, In: Cauvin, M.-C., Gourgaud, A., Gratauze, B., Arnaud, N., Poupeau, G., Poidevin, J.-L., Chataigner, C. (Eds.), L'Obsidienne L'Obsidienne au Proche et Moyen Orient: Du Volcan à l'Outil. Maison de l'Orient Méditerranéen, BAR International Series 738. Archaeopress, Oxford, pp. 241-259.

Balkan-Atl1, N., Binder, D., Cauvin, M. -C. 1999. 'Obsidian Sources, Workshops and Trade in Central Anatolia, in M. Özdoğan, and N. Başgelen eds., Neolithic in Turkey. Istanbul: Arkeoloji ve Sanat Yayınları, 133-145, figs. 104-115.

Bigazzi, G., Yeğingil, Z., Ercan,T., Oddone, M. and Özdogan M., 1993. Fission Track Dating Obsidians in Central and Northern Anatolia. Bulletin of Volcanology 55(8):588-595.

Binder, D., Gratuze, B., Mouralis, D., Balkan-Atlı, N., 2011. New investigations of the Göllüdağ obsidian lava flows system: a multi-disciplinary approach. Journal of Archaeological Science, 38 (12), pg. 3174-3184.

Chataigner, C., Poidevin, J.L., Arnaud, N.O., 1998. Turkish occurrences of obsidian and use by prehistoric peoples in the Near East from 14,000 to 6000 BP. Journal of Volcanology and Geothermal Research, Volume 85, p. 517-537.

Ercan, T., 1987. Orta Anadolu'daki Senozoyik Volkanizmasi. MTA Dergisi, 107, 119-140.

Erturaç, M.K., Astruc, L., Balkan-Atlı, N., Gratuze, B., Mouralis, D., Kuzucuoğlu, C., Dinçer, B., Kayacan, N., 2012. Göllüdağ Volkanik Kompleksi İçerisindeki Obsidiyen Kaynaklarının Özellikleri, I. Ulusal Coğrafya Sempozyumu, Bildiriler Kitabı, 28-30 May1s 2012 Erzurum.

Gevrek, A.İ. and Kazanc1, N., 2000. A Pleistocene, pyroclastic-poor maar from central Anatolia,
Turkey: influence of a local fault on a phreatomagmatic eruption. Journal of Volcanology and Geothermal Research, 95, 309-317.

Gürsoy, H., Piper, J.D.A., Tatar, O. and Mesci, B.L. 1998. Palaeomagnetic study of the Karaman and Karapınar volcanic complexes, central Turkey: neotectonic rotation in the south-central sector of the Anatolian Block. Tectonophysics, 299, p.191211.

Innocenti, F., Mazzuoli, R., Pasquarè, G., Radicati di Brozolo, F., Villari, L., 1975. The Neogene calc-alcaline volcanism of Central Anatolia: geochronological data on Kayseri- Nigde area. Geological Magazine 112, 349-360.

Kazanc1, N., Şaroğlu, F., 2003. Annual report on the projection of geological heritage in Turkey. Progeo WG1 Annual Meeting, September 22-28, Bucharest, Romania.

Kazanc1,N., 2010. Jeolojik Koruma Kavram ve Terimler. Jeolojik Mirası Koruma Derneği (JEMIRKO) yayınları, Ankara

Kazancı, N., Şaroğlu, F., Suludere, Y., 2015. Jelojik Miras ve Türkiye Jeositleri Çatı Listesi, MTA Dergisi , 151: 263-272.

Kuhn, S.L., Dincer, B., Balkan-Atli, N; Erturac, M. K., 2015. Paleolithic occupations of the Gollu Dag, Central Anatolia, Turkey, Journal of Field Archaeology Vol. 5, pp. 581-602.

Kuzucuoglu, C., Pastre, J-F., Black, S., Ercan, T., Fontugne, M., Guillou, H., Hatte, C., Karabıyıkoğlu, M., Orth P., Türkecan, A. 1998. Identification and Dating of Tephra Layers from Quaternarty Sedimentary Sequences of Inner Anatolia, Turkey. J. Volcanol. Geotherm. Res., 85, 153-172.

Kuzucuoğlu, C., Mouralis, D. and Türkecan, A. 2013. Geomorphological Mapping as an Illustration of Geomorphological Evolution Reconstruction: The Example of the Çiftlik Plain in Cappadocia (Niğde), in "Profesör Doktor İlhan Kayan'a Armağan”, Ed. Ertuğ Öner, Ege Üniversitesi Basımevi, 133-144.

Le Pennec, J.L., Bourdier, J.L., Froger, J.L., Temel, A., Camus, G., Gourgaud, A., 1994. Neogene 
Ignimbrites of the Nevşehir Plateau (Central Turkey): Stratigraphy, Distribution and Source Constraints. J. Volcanol. Geotherm. Res., 63, 5987.

Mouralis D., 2003.- Les complexes volcaniques quaternaires de Cappadoce (Göllüdağ et Acigöl - Turquie): évolutions morphodynamiques et implications environnementales. Thèse de doctorat, Université Paris XII.

Pasquarè, G., 1968. Geology of the Cenozoic volcanic area of central Anatolia. Atti Accademia Nazionale dei Lincei 9, 55-204.

Pasquare, G., Poli, S., Vezzoli, L., Zanch, A., 1988. Continental arc volcanism and tectonic setting in central Anatolia, Turkey, Tectonophysics 146, 217-230.

Renfrew, C. 1969. Trade and Culture Process in European Prehistory. Current Anthropology 10(2/3):151-169.

Roberts, N., Allcock, S.L., Arnaud, F., Dean, J.R., Eastwood, W.J., Jones, M.D., Leng, M.J., Metcalfe, S.E., Malet, S.E., Woodbridge, J., Yiğitbaşoğlu, H., 2016. Journal of Quaternary Science, 31, 348-362.

Schmitt, A.K., Danisik, M., Evans, N.J., Siebel, W., Kiemele, E., Aydın, F., Harvey, J., 2011. Petrol. 162:1215-1231.
Slimak, L., Kuhn, S., Helene, R., Mouralis, D., Bbuitehuis, H., Balkan-Atl1, N., Binder, D., Kuzucuoğlu, C., Guillou, H., 2008. Kaletepe Deresi 3 (Turkey): Archaeological evidence for early human settlement in Central Anatolia, Journal of Human Evolution 54, 99-111.

Şaroğlu, F., Kazanc1, N., Boyraz, S., 2007. Examples of anthropogenic geosites from Turkey as evidences of active seismicty and paleohazards in Late Quaternary. The 12th Regional Conference on Geoconservation and ProGEO Working Group 1 Annual Meeting. 5-9 September, 2007. Ljubljana, Slovenia.

Türkecan, A., Kuzucuoğlu, C., Mouralis, D., Pastre, J-F., Atıc1, Y., Guillou, H., Fontugne, M., 2004. Upper Pleistocene Volcanism and Paleogeography in Cappadocia, Turkey. MTA-CNRS-TUBITAK joint project report. 190 pages.

Toprak, V., 1998. Vent distribution and its relation to regional tectonics, Cappadocian Volcanics, Turkey. Journal of Volcanology and Geothermal Research, 85. 55-67.

Makale Geliş Tarihi : 20 Ağustos 2016

Kabul Tarihi : $\quad 16$ Aralık 2016

Received : 20 August 2016

Accepted : 16 December 2016 